\title{
Originals
}

\section{Delayed Progression of Diabetic Retinopathy by Divided Insulin Administration: A Further Follow-Up}

\author{
E. Eschwege ${ }^{1}$, D. Job ${ }^{1}$, C. Guyot-Argenton ${ }^{2}$, J. P. Aubry ${ }^{2}$, and G. Tchobroutsky ${ }^{3}$ \\ ${ }^{1}$ Statistical Research Unit (I. N. S. E. R. M.), ${ }^{2}$ Department of Ophthalmology, Hôtel Dieu Hospital, Paris, \\ and ${ }^{3}$ Department of Diabetes, Hôtel Dieu Hospital, Pierre and Marie Curie University, Paris, France
}

\begin{abstract}
Summary. We have previously reported a slower rate of progression in the number of microaneurysms in insulin dependent diabetic patients treated by divided insulin injections when compared to patients receiving a single daily insulin injection [Diabetes $\mathbf{2 5}$, 463-469 (1976)]. This observation is strengthened by the present analysis which uses complementary data obtained after a further year follow up: the mean yearly increase in the number of microaneurysms was $9 \pm 1$ in the single injection group and $3 \pm 1$ in the multiple one $(\mathrm{p}<0.001)$.
\end{abstract}

Key words: Randomized clinical trial, insulin dependent treatment, retinopathy, microaneurysms.

As recently emphasized [1], some prospective studies in man $[2-4$, in 4$]$ and animal [5-8] demonstrate that improvement of regulation of glucose levels may delay the occurrence of microvascular complications of diabetes. Our group reported that insulin dependent diabetics treated by multiple daily insulin injections ( $M$ group) experienced a slower rate of development of microaneurysms and a better control of diabetes than those treated by a single daily injections (S group) [4]. This paper deals with the final results of this trial, after a further year follow up, designed to verify previously reported results. The mean duration of the survey was finally about four years in both groups. Differences reached a higher level of statistical significance.

\section{Material and Methods}

A detailed description of patients' treatment, adherence to treatment and data collected has been previously published for the first three years of follow up [4]. No change occured in the fourth year except one patient of the $M$ group left the Paris area within that period and could not submit to the final examination. The trial was designed as follows: forty two insulin dependent diabetic patients were randomly assigned to two groups of treatment i. e. a single injection group and a multiple injection group. Patients of the $S$ group received long acting insulin alone or with short or intermediate acting insulin added in the same injection. Patients of the $M$ group received short acting insulin before breakfast and lunch and intermediate acting insulin with or without short acting insulin before dinner. When they refused the three injection regime, they were subjected to two injections of intermediate acting insulin, one before breakfast and one before dinner. Only the total daily insulin dosage and the number of daily injections have been recorded regardless of the type of insulin which had been chosen as the best for each patient by his physician. Retinal changes were evaluated by counting the microaneurysms of the posterior pole of the more diseased eye on angiofluorograms. No significant proliferative lesions existed either at baseline or at the end of the survey. Control of diabetes was roughly evaluated by recording 24 hour glycosuria and fasting blood sugar values at the time of quarterly clinical examination. At the beginning of the study it was realized that these variables could be poorly related to actual metabolic control, but the definition of a reliable index of metabolic control, for long term studies, remained at that time an unresolved problem. Some other clinical and biological variables, such as blood pressure, weight, serum cholesterol, serum lipids, and plasma creatinine were analyzed.

\section{Results}

Mean duration of follow-up was $49.1 \pm 3.4$ months in the $S$ group and $51.1 \pm 2.6$ months in the $M$ group (NS).

The number of microaneurysms at baseline and final examination are shown in Table 1. Statistical analysis of ophthalmological data is given in Table 2 . It shows that the increase in the number of microaneurysms was significantly lower in the $M$ than in the $S$ group $(\mathrm{p}<0.001)$. Table 3 shows that mean fasting blood sugar calculated as the mean of all individual mean values was significantly lower in the $M$ 
Table 1. Number of microaneurysms at baseline and final examinations in the two groups under comparison (for intermediate data see [4])

\begin{tabular}{|c|c|c|c|c|c|c|c|}
\hline \multicolumn{4}{|c|}{ Single injection group } & \multicolumn{4}{|c|}{ Multiple injection group } \\
\hline \multirow{2}{*}{$\begin{array}{l}\text { Patient } \\
\text { number }\end{array}$} & \multirow{2}{*}{$\begin{array}{l}\begin{array}{l}\text { Base- } \\
\text { line }\end{array} \\
14\end{array}$} & \multicolumn{2}{|c|}{$\begin{array}{l}\text { Final } \\
\text { examination }\end{array}$} & \multirow{2}{*}{$\begin{array}{l}\begin{array}{l}\text { Patient } \\
\text { number }\end{array} \\
1\end{array}$} & \multirow{2}{*}{$\begin{array}{l}\begin{array}{l}\text { Base- } \\
\text { line }\end{array} \\
2\end{array}$} & \multicolumn{2}{|c|}{$\begin{array}{l}\text { Final } \\
\text { examination }\end{array}$} \\
\hline & & 46 & (62) & & & 38 & $(59)$ \\
\hline 2 & 24 & 92 & (61) & 2 & 6 & 12 & $(60)$ \\
\hline 3 & 0 & 75 & (59) & 3 & 2 & 18 & $(60)$ \\
\hline 4 & 0 & 50 & $(60)$ & 4 & 11 & 9 & (59) \\
\hline 5 & 4 & 6 & (59) & 5 & 15 & 71 & (62) \\
\hline 6 & 0 & 52 & (64) & 6 & 8 & 18 & (45) \\
\hline 7 & 12 & 56 & (60) & 7 & 19 & 55 & (52) \\
\hline 8 & 0 & 6 & (60) & 8 & 1 & 1 & (25) \\
\hline 9 & 39 & 64 & $(60)$ & 9 & 1 & 12 & (58) \\
\hline 10 & 10 & 49 & (23) & 10 & 26 & 18 & $(57)$ \\
\hline 11 & 16 & 78 & (57) & 11 & 1 & 14 & $(52)$ \\
\hline 12 & 1 & 40 & (57) & 12 & 1 & 9 & (63) \\
\hline 13 & 0 & 10 & (14) & 13 & 2 & 56 & (58) \\
\hline 14 & 3 & 27 & (42) & 14 & 0 & 6 & $(57)$ \\
\hline 15 & 7 & 8 & (28) & 15 & 1 & 6 & (30) \\
\hline 16 & 3 & 36 & (50) & 16 & 5 & 60 & (57) \\
\hline 17 & 9 & 126 & (61) & 17 & 1 & 18 & (54) \\
\hline 18 & 63 & 130 & (48) & 18 & 3 & 2 & (20) \\
\hline 19 & 8 & 9 & (16) & 19 & 10 & 16 & $(50)$ \\
\hline 20 & 30 & 104 & (43) & 20 & 5 & 44 & (51) \\
\hline 21 & 21 & 90 & (48) & 21 & 68 & 144 & (44) \\
\hline
\end{tabular}

In parentheses: time in months from baseline examination

Table 2. Comparison of the progression of microaneurysms between the two groups (mean \pm SEM)

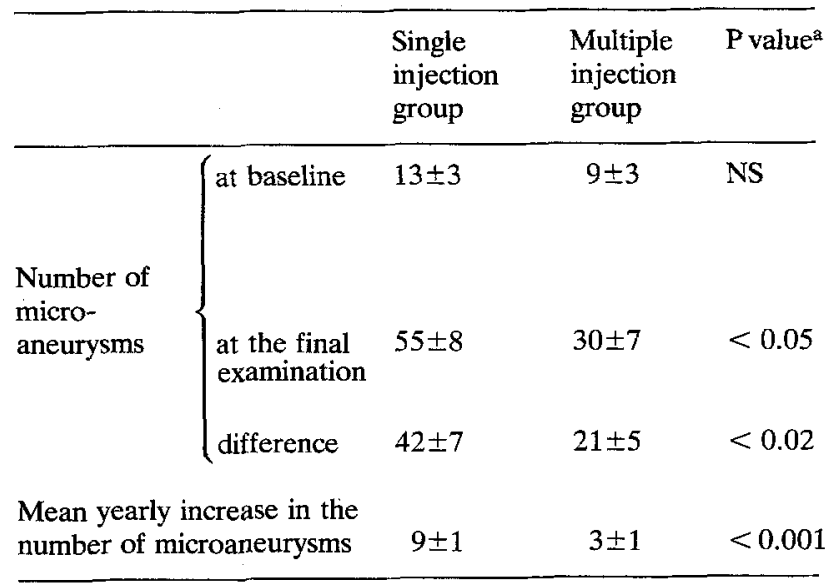

a $\mathrm{P}$ Value is given for non parametric test (Mann and Whitney)

than in the S group during the whole survey. Mean 24 hour glycosuria did not differ. Nevertheless it showed a tendency to decrease in the $M$ group and variations from baseline values differed between the two groups. The correlation between fasting blood sugar or $24 \mathrm{hr}$ glycosuria and the progression of retinal lesions did not reach the $5 \%$ significance level in either group. Mean daily insulin dosage did not differ
Table 3. Control of diabetes: Mean \pm SEM

\begin{tabular}{|c|c|c|c|}
\hline & $\begin{array}{l}\text { Single in- } \\
\text { jection group }\end{array}$ & $\begin{array}{l}\text { Multiple in- } \\
\text { jection group }\end{array}$ & P Value \\
\hline $\begin{array}{l}\text { Mean fasting blood } \\
\text { sugar }(\mathrm{mg} / 100 \mathrm{ml}) \\
\text { Mean } 24 \text { hour }\end{array}$ & $192 \pm 8$ & $166 \pm 9$ & $<0.05$ \\
\hline $\begin{array}{l}\text { glycosuria }(\mathrm{g} / 24 \mathrm{~h}) \\
\text { Variation of } 24 \text { hour } \\
\text { glycosuria from }\end{array}$ & $27 \pm 4$ & $24 \pm 3$ & NS \\
\hline $\begin{array}{l}\text { baseline }(\mathrm{g} / 24 \mathrm{~h}) \\
\text { Mean daily insulin } \\
\text { dosage }(\mathrm{U} / 24 \mathrm{~h})\end{array}$ & $+5 \pm 4$ & $-5 \pm 3$ & $<0.05$ \\
\hline
\end{tabular}

Table 4. Mean value of clinical and biological variables during the survey (mean $\pm \mathrm{SEM}$ )

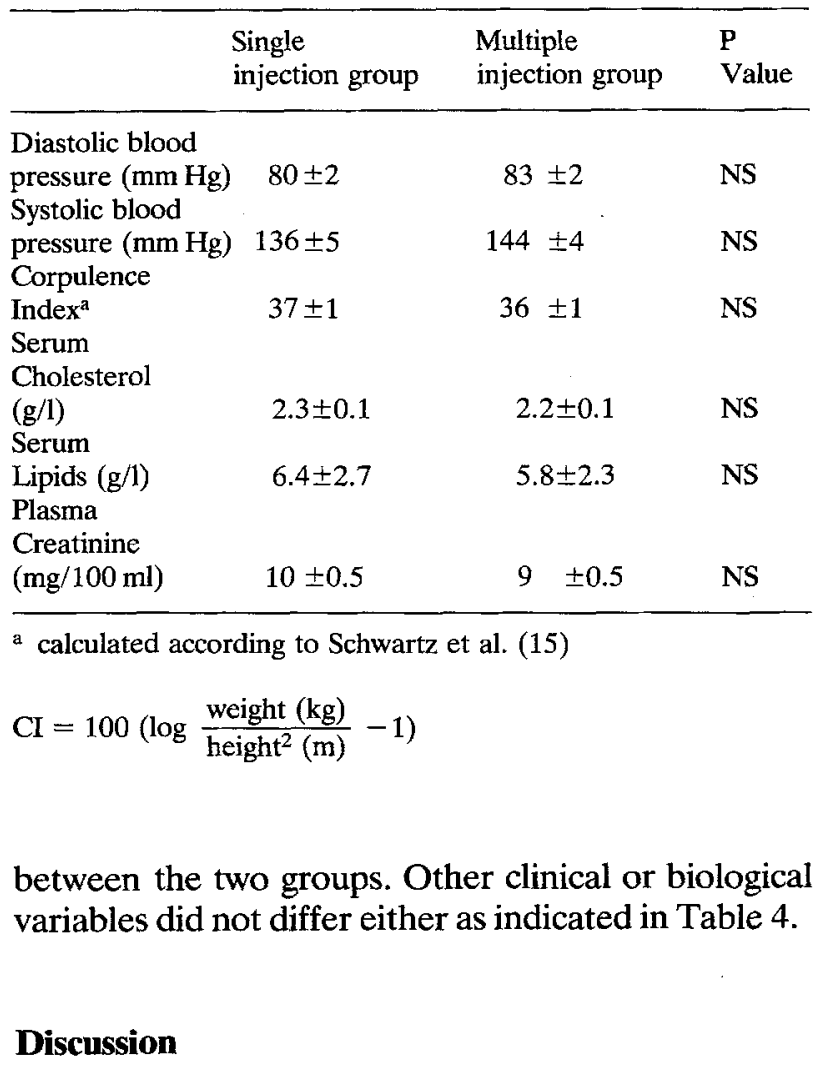

The present analysis, using complementary data, strengthens our previous report of a slower rate of progression of microaneurysms in insulin dependent diabetics treated with multiple daily insulin injections when compared to patients treated with a single daily injection [4].

It can be questioned whether a slower increase in the number of microaneurysms is really beneficial. Thus it could be hypothesized that slower development of these lesions could be due to faster extension of areas of vascular non perfusion. Although this might be true for an individual patient, there is evidence that, in terms of means, the increase of the 
number of microaneurysms tends to parallell the aggravation of diabetic retinopathy. Previous transvers studies by our group showed that the number of microaneurysms correlates with the duration of the disease and with the plasma creatinine levels [9].

Furthermore we have verified that the mean number of microaneurysms is consistently higher in patients with proliferative lesions than in patients with background retinopathy. Whether this relation is causal or not, a high number of microaneurysms is a risk factor for development of proliferative retinopathy. It has been questioned how far significant differences observed in groups of limited size are reliable [10]. It must be emphasized that we used statistical techniques designed for small size samples, non normal distribution and non equal variances. These included square root transformation and non parametric tests. Unfortunately, there is no way to measure the risk of extrapolating to large populations the results obtained in highly selected groups.

It has also been emphasized [10] that only four of the 21 patients actually received three injections of insulin per day during the whole trial. In fact the trial was designed to compare single to multiple (two or three) insulin regimes. Furthermore in the $\mathbf{M}$ group 13 patients at least remained with three daily injections of insulin during a mean duration of one year [4].

The intimate mechanisms of the apparent effect of dividing insulin administration through the day might be due to:

1) differences of the type of insulin. This hypothesis seems at least unlikely;

2) differences of the quality of general management of diabetics, related to the psychological effect of treatment by multiple daily injections. This hypothesis cannot be ruled out because it was not possible to use placebo insulin injections in the $S$ group;

3) differences in metabolic control: although this hypothesis underlies our study, its validity could not be unambiguously assessed since the effect of treatment on retinal changes was much more significant than their effect on fasting blood sugar or 24 hour glycosuria. This observation could be explained by the lack of reliability of these investigations as indices of metabolic control [11]. Since the beginning of our study, it has been claimed that measurement of glycosylated hemoglobin provides a reliable estimation of diabetic control [12-14]. It would be therefore of interest to verify that changes in the number of daily insulin injections do modify this variable in randomized groups of patients.

Acknowledgements. This study was supported by Institut National de la Santé et de la Recherche Médicale, la Caisse Nationale de l'Assurance Maladie des Travailleurs Salariés et l'Association
Française pour l'Etude de l'Epidémiologie du Diabète. We thank A. Fenelon for technical assistance.

\section{References}

1. Cahill, G. F., Etzwiler, D., Freinkel, N.: Control and diabetes. N. Engl. J. Med. 294, 1004 (1976)

2. Takazakura, E., Nakamoto, Y., Havakawa, H., Kawai, K., Muramoto, S., Yoshide, K., Saathoff, J., Guthrie, D.: Onset and progression of diabetic glomerulosclerosis. Diabetes $\mathbf{2 4}$, 1-9 (1975)

3. Jackson, R., Guthrie, R., Esterly, J., Bilginturan, N., James, R., Yeast, J., Saathoff, J., Guthrie, D.: Muscle capillary basement membrane changes in normal and diabetic children. Diabetes 24 [Suppl. 2], 400 (1975)

4. Job, D., Eschwege, E., Guyot-Argenton, C., Aubry, J. P., Tchobroutsky, G.: Effect of multiple daily insulin injections on the course of diabetic retinopathy. Diabetes 25, 463-469 (1976)

5. Mauer, S. M., Sutherland, D. E. R., Steffes, M. W., Léonard, R. J., Najarian, J. S., Michael, A. F., Brown, D. M.: Pancreatic islet transplantation. Diabetes 23, 748-753 (1974)

6. Mauer, S. M., Steffes, M. W., Sutherland, D. E. R., Najarian, J. S., Michael, A. F., Brown, M. D.: Studies of the role of regression of the glomerular lesions in diabetic rats treated with pancreatic islet transplantation. Diabetes 24, 280-285 (1975)

7. Hägg, E.: On the pathogenesis of glomerular lesions in the alloxan diabetic rat. Acta Med. Scand. [Suppl.] 558, 1-31 (1974)

8. Engerman, R. L., Bloodworth, J. M. B., Nelson, S.: Relationships of microvascular disease in diabetes to metabolic control. Diabetes 26, 760-779 (1977)

9. Job, D., Eschwege, E., Tchobroutsky, G., Guyot-Argenton, C., Aubry, J. P., Derot, M.: Diabetic retinopathy, duration of diabetes and risk factors of atherosclerotic cardiovascular disease. Acta Diabetol. Lat. 12, 1-8 (1975)

10. Siperstein, M. D., Forster, D. W., Knowles, H. C., Levine, R., Madison, L. L., Roth, J.: Control of blood glucose and diabetic vascular disease. N. Engl. J. Med. 296, 1060-1063 (1977)

11. Lefebvre, P., Milet, J., Luyckx, A.: Control of diabetes: an attempt to formulate policy guidelines in a department of medicine. Diabetologia 10, 201-204 (1976)

12. Gabbay, K. H., Hasty, K., Breslow, J. L., Ellison, R. C., Bunn, H. F., Gallop, P. M.: Glycosylated hemoglobins and long-term blood glucose control in diabetes mellitus. J. Clin. Endocrinol. Metab. 44, 859-864 (1977)

13. Koenig, R. J., Peterson, C. M., Jones, R. L., Saudek, C., Lehrman, M., Cerami, A.: Correlation of glucose regulation and hemoglobin $A_{I C}$ in diabetes mellitus. N. Engl. J. Med. 295, 417-420 (1976)

14. Lanoé, R., Soria, J., Thibult, N., Soria, C., Eschwege, E., Tchobroutsky, G.: Glycosylated haemoglobin concentrations and clinitest results in insulindependent diabetes. Lancet: 1977 II, 1156-1157

15. Schwartz, D., Lellouch, J., Anguera, G., Beaumont, J. L., Lenegre, J.: Tobacco and other factors in the aetiology of ischemic heart disease in men. Results or a retrospective survey. J. Chronic Dis. 19, 35-36 (1966)

Received: August 3, 1977,

and in revised form: July 24, 1978

\section{E. Eschwege}

Unité de Recherches Statistiques

16 bis av. P. V. Couturier

F-94800 Villejuif

France 